\title{
Incidence of sickle cell disease patients with pulmonary embolism admitted to the intensive care unit in Bahrain
}

Fatema H. Mandeel, MD, MBBCH, Hasan M. Saeed, MBBS, MD, Abmed H. Alsadah, MD, MBBCH, Sara A. Ahmed, MBBS, MD, Redha A. Al hammam, BSc, General Nursing.

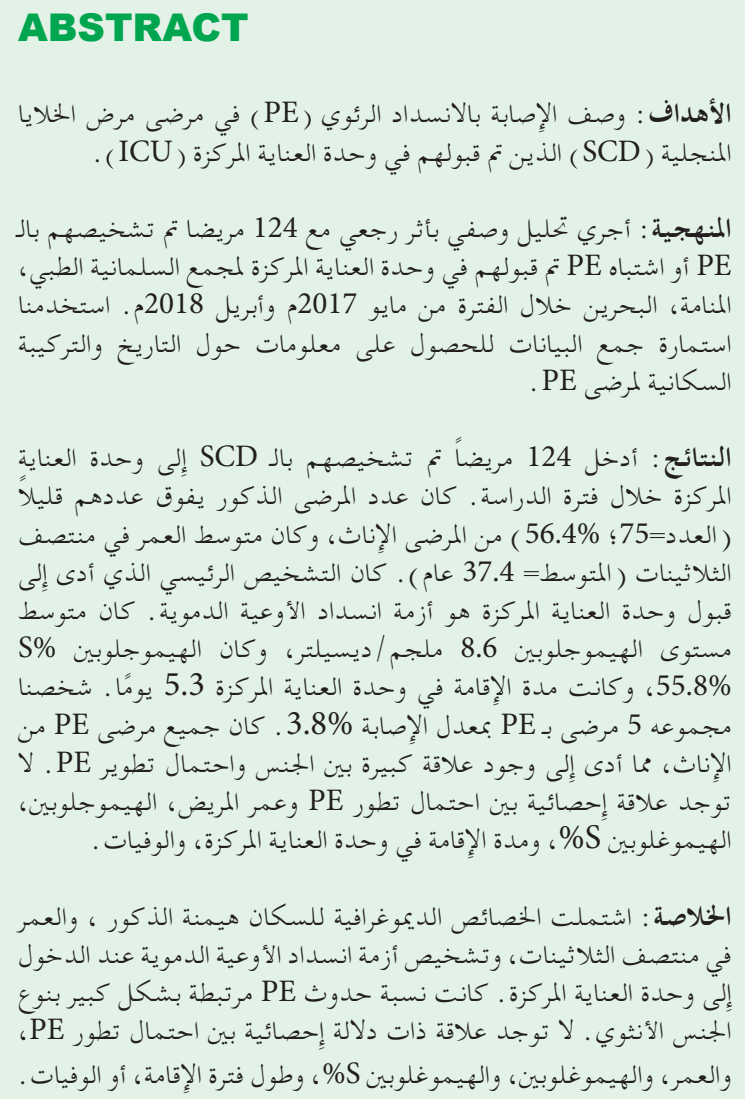

Objectives: To describe the incidence of pulmonary embolism (PE) in sickle cell disease (SCD) patients admitted to the intensive care unit (ICU).

Methods: A retrospective descriptive analysis was conducted with 124 SCD patients diagnosed with PE or suspected PE admitted to the ICU of Salmaniya Medical Complex, Manama, Bahrain between May 2017 and April 2018. A data collection form was used to obtain information on the history and demographics of PE patients.

Results: A total of 124 patients diagnosed with SCD were admitted to the ICU during the study period.
Male patients slightly outnumbered ( $\mathrm{n}=75 ; 56.4 \%)$ female patients, and the average age was in the midthirties (mean $=37.4$ years). The main diagnosis leading to ICU admission was vaso-occlusive crisis. The average hemoglobin level was $8.6 \mathrm{mg} / \mathrm{dl}$, hemoglobin S\% was $55.8 \%$, and the length of stay in the ICU was 5.3 days. A total of 5 patients were diagnosed with $\mathrm{PE}$ with an incidence rate of $3.8 \%$. All PE patients were females, which resulted in a significant relationship between gender and the likelihood of developing PE. No statistical relationship existed between the likelihood of developing PE and patient age, hemoglobin, hemoglobin $\$ \%$, length of stay in ICU, and mortality.

Conclusion: The demographic characteristics of the population included a male predominance, age in the mid-thirties, and vaso-occlusive crisis diagnosis upon admission to the ICU. The incidence of PE was significantly related to female gender. No significant relationship existed between the likelihood of developing PE and age, hemoglobin, hemoglobin S\%, length of ICU stay, or mortality.

Keywords: ICU, PE, SCD, VOC

Saudi Med J 2020; Vol. 41 (8): 802-807 doi: $10.15537 /$ smj.2020.8.25170

From the Department of Internal Medicine, Salmaniya Medical Complex, Manama, Bahrain.

Received 31st March 2020. Accepted 8th June 2020.

Address correspondence and reprint request to: Dr. Fatema H. Mandeel, Department of Internal Medicine, Salmaniya Medical Complex, Manama, Bahrain.E-mail: Dr.mandeel124@gmail.com ORCID ID: htttps://orcid.org/0000-0001-8981-2395

Disclosure. Authors have no conflict of interests, and the work was not supported or funded by any drug company. 
$S_{d}^{\mathrm{i}}$ ickle cell disease (SCD) is a group of inherited diseases that affect hemoglobin, which delivers oxygen to cells throughout the body. Patients with this disorder have atypical hemoglobin molecules called hemoglobin S (HbS) or sickle hemoglobin. Sickle cell disease is inherited in an autosomal recessive pattern. ${ }^{1}$ Vascular obstruction due to the distorted sickle shape of red blood cells (sickling) and endothelial adherence to erythrocytes can result in damage to different organs or systems. ${ }^{2}$ The most common complications associated with SCD include vaso-occlusive crisis (VOC), severe anaemia, infection, acute chest syndrome, thromboembolism, multiorgan failure with poor outcome and early mortality. ${ }^{3-5}$

Venous stasis, turbulent blood flow, and a hypercoagulable state often cause deep venous thrombosis (DVT) and pulmonary embolism (PE). ${ }^{6}$ Patients with SCD exhibit an elevated baseline level of coagulation and are at an increased risk for venous thrombosis and PE.7.8 Factors associated with thrombosis and embolism include cancer, trauma, infection, obesity, and recent lower extremity orthopedic surgery. ${ }^{6,9-11}$

The prevalence of $\mathrm{PE}$ is higher for hospitalized SCD patients than for non-SCD patients and is likely under-diagnosed. ${ }^{7,12}$ Treatment of PE can greatly reduce mortality. ${ }^{13}$ Sickle cell disease is much more common in certain ethnic groups and is considered one among the most prevalent genetic blood disease within the Gulf region, including Bahrain. In a study by Al-Arrayed et al, ${ }^{14} 56198$ blood tests of Bahraini individuals were analyzed over 6 years. Sickle cell disease prevalence was reported as $2.1 \%$. The study described that the mild type of SCD among Bahrainis was predominant, but wide clinical variability was apparent. ${ }^{14}$

Although life expectancy of SCD patients has drastically improved, pulmonary complications attribute to a high death rate among young individuals. ${ }^{15}$ For instance, Alkhawaja et al, ${ }^{16}$ concluded that the death rate of SCD patients was $12.7 \%$ among 210 patients in the intensive care unit (ICU) of the Salmaniya Medical Complex (SMC), which is the largest and core government hospital in Bahrain. Comparing to non-SCD patients, PE incidence is higher in SCD patients, suggesting that PE may be under-diagnosed. ${ }^{12}$

Due to the lack of information about the incidence and demographic characteristics of SCD patients with $\mathrm{PE}$ and suspected PE admitted to the ICU in the SMC hospital in Bahrain, a retrospective descriptive analysis was performed in this study to help ICU staff identify SCD patients at highest risk of PE in the Kingdom of Bahrain.
Methods. The study was carried out at the ICU department with a 22 bed capacity in Salmaniya Medical Complex (SMC), Manama, Bahrain which is the largest tertiary teaching and the central government hospital in Manama, Bahrain.

All SCD patients $(n=124)$ were admitted to the ICU with a diagnosis of PE or suspected PE during the period between May 2017 and April 2018. All patients with $\mathrm{PE}$ were diagnosed upon admission.

The study design was retrospective and descriptive. The inclusion criteria included all SCD patients admitted to the ICU during this period despite age, gender, comorbidities or number of admissions and the exclusion criteria was non-SCD patients with PE.

Data collection. The research team developed a data collection form. The study was authorized by the Secondary Health Care Research Sub Committee, SMC. Moreover, formal consent was obtained from patients prior to the completion of data forms. The form included the patient's name, gender, age, admission diagnosis, hemoglobin $(\mathrm{Hb})$ and hemoglobin $\mathrm{S} \%(\mathrm{HbS} \%)$ on admission, ICU length of stay, comorbidities and computed tomography (CT) angiography findings. Patient's data was collected from the registration book and the electronic I-Seha. Meticulous care was taken during the identification of data and data entry. Multiple measures were taken to ensure data accuracy.

Statistical analysis. The Statistical Package for Social Sciences, version 20 (IBM Corp, Armonk, NY, USA) was used to analyze the collected data. Descriptive and inferential statistics for demographic variables, illnessrelated variables and PE incidence were conducted. The variables relations were investigated with the proper statistical methods ( $\mathrm{t}$-test, ANOVA, Pearson correlation and Chi-square test).

Results. Information on patient's gender and age is listed in Table 1. The sample consisted of 124 patients with a total of 133 admissions to the ICU. Male patients $(\mathrm{n}=75,56.4 \%)$ slightly outnumbered their female counterparts $(n=58,43.6 \%)$. On average, the study participants were fairly young and in their mid-thirties (mean=37.4 years). Despite the mean age of males being 4 years older than that of females, the difference was not statistically significant.

Diagnosis. In addition to their principal diagnosis as SCD patients, the sample presented with approximately 20 different admitting diagnoses, as shown in Table 2. The predominant admitting diagnosis was VOC, as it was reported in $62.4 \%$ of the cases. This diagnosis was followed by gastrointestinal (GI) conditions (9.8\%), gynecological conditions (7.5\%), and acute chest 
syndrome and chest infection (4.5\%). The rate of orthopedic conditions reported to be $3.8 \%$ and that of $\mathrm{PE}$ was $3.7 \%$. The least common diagnosis was anemia $(3 \%)$ and other conditions (2.2\%). Some of the patients were admitted with more than one diagnosis.

Hemoglobin, HbS\% on admission and length of stay in the ICU. The SCD subjects had an average hemoglobin of $8.6 \mathrm{mg} / \mathrm{dl}$. Moderate variability among the subjects was reflected by a standard deviation of 2.2 , as shown in Table 3.

The average $\mathrm{HbS} \%$ was relatively high (mean $=55.8 \%$ ), with noticeable variation among the subjects, as evidenced by a high standard deviation (21.1).

The sample has an average length of stay (LOS) of 5.3 days. A very noticeable variation among the SCD subjects in this regard was reflected by a relatively large standard deviation of 6.4 days.

Incidence of pulmonary embolism. Among the 133 reviewed admissions of SCD patients to the ICU, only 5 patients were diagnosed with PE. This resulted in an incidence rate of approximately $3.8 \%$.

Incidence of PE and gender. All the SCD patients diagnosed with PE were females $(n=5)$, representing $8.6 \%$ of the total females in the sample $(n=58)$. This finding suggests that there might be a relationship

Table 1 - Information on patient's gender and age.

\begin{tabular}{lcc}
\hline Variables & $\mathrm{n}(\%)$ & $P$-value \\
\hline Gender & & \\
Male & $75(56.4)$ & \\
Female & $58(43.6)$ & \\
Age (mean) & & $0.140^{*}$ \\
Male & 39.4 & \\
Female & 35.8 & \\
Total & 37.4 & \\
\hline
\end{tabular}

*According to independent sample t-test at alpha $=0.05$

Table 2 - Sickle cell disease patients admitted with different diagnoses.

\begin{tabular}{lr}
\hline Diagnosis & n (\%) \\
\hline Vaso-occlusive crisis & $83(62.4)$ \\
GI conditions (stomach, spleen, liver, and so on) & $11(9.8)$ \\
Gynaecologic conditions & $10(7.5)$ \\
Acute chest syndrome & $6(4.5)$ \\
Chest infection & $6(4.5)$ \\
Orthopaedic conditions & $5(3.8)$ \\
Pulmonary embolism & $5(3.7)$ \\
Anaemia & $4(3.0)$ \\
Other conditions & $3(2.2)$ \\
Total & $133(100)$ \\
\hline \multicolumn{2}{c}{ GI: gastrointestinal } \\
\hline
\end{tabular}

GI: gastrointestinal between the patient's gender and his/her likelihood of developing PE. This possibility is further supported by the statistically significant results of the Chi-square test $\left(\mathrm{X}^{2}=6.7, p=0.015\right)$ (Table 4).

Incidence of PE and age, $\mathrm{Hb}$ and $\mathrm{HbS} \%$ on admission and LOS in the ICU. There was no relationship between the subjects' ages and their chances of developing PE. Both groups (negative PE and positive PE) were very similar in age on average without statistically significant differences.

No relationship existed between the patient's $\mathrm{Hb}$ on admission and his/her likelihood of developing PE. This finding was confirmed with a statistically nonsignificant $\mathrm{t}$-test $(\mathrm{t}=0.62, p=0.511)$ since the difference between the mean $\mathrm{Hb}$ of patients with $\mathrm{PE}$ and that of their counterparts was not large enough.

No relationship existed between the patient's HbS\% on admission and his/her likelihood of developing PE. This finding was confirmed with a statistically nonsignificant $\mathrm{t}$-test $(\mathrm{t}=0.01, p=0.991)$. The difference between the mean $\mathrm{HbS} \%$ of patients with $\mathrm{PE}$ and that of their counterparts was not large enough.

No relationship existed between the patient's LOS at the ICU and his/her likelihood of developing PE. This finding was confirmed with a statistically nonsignificant $\mathrm{t}$-test $(\mathrm{t}=0.188, p=0.851)$ since the difference between the mean LOS of patients with PE and that of their counterparts was not large enough.

Discussion. Micro-and macrovasculature occlusion is the most important pathophysiological occurrence in SCD and explains most of its clinical manifestations. ${ }^{2}$ Sickle cell disease patients had significantly higher risk for venous thromboembolism, PE and DVT, comparing to non SCD adults. ${ }^{17}$ The age of 42 years for men and 48 years for women were the median age of death. ${ }^{4}$ Pulmonary embolism and thrombosis are usually caused by clotting disorders, decreased mobility, recent history of surgical procedure, obesity, cancer, deep venous thrombosis, pregnancy or post partum..$^{7-9,18,19}$ Risk factors for venous thromboembolism recurrence in SCD included lower extremity DVT as the incident event, pneumonia or acute chest syndrome. ${ }^{20}$

In SMC, the 22 adult beds in the ICU admit both medical and surgical cases, including trauma patients. Sickle cell disease with VOC was the principal reason for admission ( $\mathrm{n}=83,62.4 \%$ ), accounting for more than two-thirds of cases. This high percentage is due to the possibility of rapid clinical status deterioration in some cases and poor outcome, which necessitates ICU care. ${ }^{21,22}$ Gastroenterological complications related to SCD were found in 11 patients. Ten SCD patients 
Table 3 - Hemoglobin and hemoglobin S\% on admission and length of stay in the ICU.

\begin{tabular}{lcccc}
\hline Variable & Median & Mean \pm SD & Minimum-Maximum & Range \\
\hline Hemoglobin & 9 & $8.6 \pm 2.2$ & $2-16.1$ & 14.1 \\
Hemoglobin S\% & 57 & $55.8 \pm 21.1$ & $2-89.8$ & 87.8 \\
Length of stay in the ICU & 3 & $5.3 \pm 6.4$ & $1-45$ & 44 \\
\hline
\end{tabular}

ICU: intensive care unit, SD: standard deviation

Table 4 - Incidence of pulmonary embolism (PE) and gender.

\begin{tabular}{lcc}
\hline Gender & \multicolumn{2}{c}{ Incidence of PE in percentage $(\%)$} \\
\hline & Positive & Negative \\
Male & 0 & 100 \\
Female & 8.6 & 91.4 \\
\hline
\end{tabular}

with gynecological conditions were transferred to the ICU either with low $\mathrm{Hb}$ or post-labor for observation. Acute chest syndrome was present in 6 cases, and chest infection was present in another 6 cases. Five patients were admitted to our ICU with orthopaedic conditions related to SCD, and $\mathrm{PE}$ was found in another 5 patients. The least common diagnosis among SCD patients was anemia. Other conditions included pulmonary hypertension, acute tonsillitis and decompensated cardiomyopathy. In other studies, the primary reason of ICU admission was acute chest syndrome (ACS) with 55\% in Bahrain, 69.9\% in Oman, and 30.4\% in the United Kingdom. ${ }^{16,22,23}$ The reason was that some patients were shown to have more than one complaint and more than one organ involved, which may be related to the nature of SCD and the pathophysiological sickling process.

In the ICU, the level of $\mathrm{Hb}$ at the time of admission was $8.6 \mathrm{mg} / \mathrm{dl}$. This finding was similar to those of other studies, with $8.6 \mathrm{mg} / \mathrm{dl}$ in survivors and $8.7 \mathrm{mg} / \mathrm{dl}$ in nonsurvivors in Bahrain; and, $8.3 \mathrm{mg} / \mathrm{dl}$ in survivors and $8.6 \mathrm{mg} / \mathrm{dl}$ in nonsurvivors in Oman. ${ }^{16,23}$ At admission, the mean $\mathrm{HbS}$ was $55.8 \%$ with a standard deviation of 2.2. The Omani study revealed the mean $\mathrm{HbS}$ was $63 \%$ in survivors with a standard deviation of $21.5 \%$ and $54.5 \%$ in non-survivors with a standard deviation of $25.2 .^{23}$

In this study, ICU LOS extended between 1 to 45 days, and the average stay was 5.3 days. Our findings were similar to those of earlier Bahraini and Omani studies. $^{16,23}$ While in New York, United States of America (USA), average hospital LOS was 15.35 days with average ICU LOS of 3.63 days of 141 adults SCD patients over a 6 year period. ${ }^{24}$ This result can be attributed to the nature and complexity of the disease and the need for intensive supportive measures. The other explanation could be the delay of transfer to the ICU.

Among SCD patients admitted to the ICU, 5 patients were diagnosed with PE. This resulted in an incidence rate of $3.8 \%$. In California, USA, among 6237 SCD patients, $11.2 \%$ developed incident venous thromboemblosim: $51.6 \%$ had PE $( \pm$ DVT $), 25.7 \%$ had lower extremity DVT and $22.7 \%$ had upper extremity DVT. ${ }^{25}$ In Pennsylvania, USA, from 2001-2006, PE incidence was 50-100 folds higher in the SCD population comparing to the general population. ${ }^{12}$ Our study revealed that all SCD patients diagnosed with PE were female $(\mathrm{n}=5)$, resulting in a significant difference according to gender $(p=0.015)$. This suggests a possible relationship between patient gender and the likelihood of developing PE. However, the sample size was not large and is susceptible to changes in the future. There was no relationship between patient age and the chance of developing PE, as both SCD patients with PE (mean=38.6) and without PE (mean=37.3) had very similar ages on average.

According to our analysis, no relationship existed between the patients' $\mathrm{Hb}$ and $\mathrm{HbS} \%$ on admission and the likelihood of developing PE. The majority of SCD patients were admitted for some time in the ward and received simple blood transfusion or exchange transfusion to improve microvascular perfusion. This might have masked the role of the $\mathrm{Hb}$ and $\mathrm{HbS} \%$ level at the time of admission. ${ }^{26-28}$ No relationship was found between the length of ICU stay and the likelihood of developing PE, which was statistically nonsignificant in the t-test $(p=0.851)$. Most patients in the ICU were transferred from wards following a couple of days, while others were immediately transferred from accident and emergency departments, depending on illness severity. ${ }^{16}$

None of the patients who had PE died during their stay in the ICU. This suggests the absence of a relationship between PE development and mortality $(p=0.891)$. Three deaths occurred in the ICU among SCD patients in our study. The first patient was admitted with VOC, the second patient was admitted with drug overdose, and the third patient had VOC on renal replacement therapy due to end-stage kidney disease. Alkhawaja et $\mathrm{al}^{16}$ studied the indices of raised 
mortality rate in SCD patients were older age, less frequent hospitalization, shorter stay in the ICU and the need for renal replacement therapy. In New York, USA, their study revealed that vital signs, other than an increased respiratory rate, elevated blood urea nitrogen level, thrombocytopenia, high reticluocyte counts, and lower haptoglobin counts were predictors of ICU mortality for SCD patients. ${ }^{29}$ Similarly, in the UK study, no basic demographics presented a statistically significant association with mortality risk. ${ }^{22}$ In the Pensylvania, USA study, no distinctive clinical or laboratory parameters were predicted of PE. ${ }^{12}$

Study limitations. The sample size was not large, which can be overcome in the future by performing prospective research that includes more variables and that is conducted over several years. Our study has some major strengths despite these limitations. First, it is a study describing the incidence and demographic characteristics of SCD patients with PE in Bahrain. Second, the study raises awareness among SCD patients regarding early hospital presentation. Third, it encourages a change in hospital protocols in regard to approaching SCD patients with suspected PE and providing early treatment, which reduces mortality significantly.

In conclusion, SCD is a common hematological genetic disorder in Bahrain. The demographic characteristics included a male predominance, age in the mid-thirties and VOC diagnosed upon admission to the ICU. The incidence of PE was significantly related to female gender. No relationship existed between the likelihood of developing $\mathrm{PE}$ and age, $\mathrm{Hb}$ and $\mathrm{HbS} \%$ on admission, length of stay in the ICU, or mortality.

Acknowledgment. The authors gratefully acknowledge Dr. Qaher A. Mandeel for editing the manuscript. We would also like to thank American Journal Experts (www.aye.com) for English proofreading.

\section{References}

1. Bender M, Hobbs W, Pagon R, Bird T, Dolan C, Stephens Stephens K. Sickle Cell Disease in: GeneReviews Seattle. Seattle (WA): University of Washington. 2017.

2. Vichinsky EP, Neumayr LD, Earles AN, Williams R, Lennette ET, Dean D, et al. Causes and outcomes of the acute chest syndrome in sickle cell disease. National Acute Chest Syndrome Study Group. N Engl J Med 2000; 342: 1855-1865. [published correction appears in N Engl J Med 2000; 343: 824]

3. Chiang EY, Frenette PS. Sickle cell vaso-occlusion. Hematology/ Oncology Clinics of North America 2005; 19: 771-784.

4. Platt OS, Brambilla DJ, Rosse WF, Milner PF, Castro O, Steinberg $\mathrm{MH}$, et al. Mortality in sickle cell disease. Life expectancy and risk factors for early death. N Engl J Med 1994; 330: 1639-1644.
5. Powars D, Powars DR, Chan LSL, Hiti A, Ramicone E, Johnson C. Outcome of sickle cell anemia: a 204-decade observational study of 105. Six patients outcome of sickle cell Anemia. Medicine (Baltimore) 2005; 84: 363-376.

6. Buckwalter J, Einhorn T, O'keefe R. Orthopedic basic science: foundation of clinical practice. Thromboembolism and pulmonary distress in the setting of orthopaedic surgery. 3rd ed. Rosemont (IL): American Academy of Orthopaedic Surgeons; 2007. p. 105-113.

7. Stein PD, Beemath A, Meyers FA, Skaf E, Olson RE. Deep venous thrombosis and pulmonary embolism in hospitalized patients with sickle cell disease. Am J Med 2006; 119: 897.

8. Austin H, Key NS, Benson JM, Lally C, Dowling NF, Whitsett $\mathrm{C}$, et al. Sickle cell trait and the risk of venous thromboembolism among blacks. Blood 2007; 110: 908-912.

9. Burnham JM, Broussard M, Milbrandt T. Bilateral pulmonary embolism in an adolescent with sickle cell disease and a recent total hip arthroplasty: a case report and review of the literature. Iowa Orthop J 2014; 34: 107-110.

10. Laporte S, Mismetti P, Décousus H, Uresandi F, Otero R, Lobo $\mathrm{JL}$, et al. Clinical predictors for fatal pulmonary embolism in 15,520 patients with venous thromboembolism: findings from the registro informatizado de la enfermedad tromboembolica venosa (RIETE) registry. Circulation 2008; 117: 1711-1716.

11. Miller MD, Hart JA. Basic sciences. In: Brinker MR, O'Connor DP, editors. Review of orthopaedics. Philadelphia (PA): Elsevier; 2008. p. 94-97.

12. Novelli EM, Huynh C, Gladwin MT, Moore CG, Ragni MV. Pulmonary embolism in sickle cell disease: a case-control study. J Thromb Haemost 2012; 10: 760-766.

13. Hermann RE, Davis JH, J Holden WD. Pulmonary embolism. A clinical and pathologic study with emphasis on the effect of prophylactic therapy with anticoagulants. Am J Surg 1961; 102: 19-28.

14. Al Arrayed, SS. Haites, Haites N. Features of sickle-cell disease in Bahrain. East Mediterr Health J 1995; 1: 112-119.

15. Gladwin MT, Vichinsky E. Pulmonary complications of sickle cell disease. $N$ Engl J Med 2008; 359: 2254-2265.

16. Al Khawaja SA, Ateya ZM, Al Hammam RA. Predictors of mortality in adults with sickle cell disease admitted to intensive care unit in Bahrain. J Crit Care 2017; 42: 238-242.

17. Noubiap JJ, Temgoua MN, Tankeu R, Tochie JN, Wonkam A, Bigna JJ. Sickle cell disease, sickle trait and the risk for venous thromboembolism: a systematic review and meta-analysis. Thromb J 2018; 16: 27.

18. Mont MA, Jacobs JJ, Boggio LN, Bozic KJ, Della Valle CJ, Goodman SB, et al. Preventing venous thromboembolic disease in patients undergoing elective hip and knee arthroplasty. $J \mathrm{Am}$ Acad Orthop Surg 2011; 19: 768-776.

19. Lazo KG, Eldredge JB, Press A, Mina BA. Pulmonary complications of sickle cell disease in the pregnant patient. Int J RespirPulm Med 2017; 4: 73.

20. Brunson A, Keegan T, Mahajan A, White R, Wun T. High incidence of venous thromboembolism recurrence in patients with sickle cell disease. Am J Hematol 2019; 94: 862-870.

21. Cecchini J, Lionnet F, Djibré M, Parrot A, Stojanovic KS, Girot $\mathrm{R}$, et al. Outcomes of adult patients with sickle cell disease admitted to the ICU: a case series. Crit Care Med 2014; 42: 1629-1639.

23. Tawfic QA, Kausalya R, Al-Sajee D, Burad J, Mohammed AK, Narayanan A. Adult sickle cell disease: a five-year experience of intensive care management in a university hospital in Oman. Sultan Qaboos Univ Med J 2012; 12: 177-183. 
24. Rosentsveyg J, Simonson JL, Chung SY, Koenig Sj, Zaidi GZ. A retrospective study of patient demographics, therapeutic management, and outcomes of sickle cell disease in the intensive care unit. Am J Respir Crit Care Med 2019; 201: A3436.

25. Brunson A, Lei A, Rosenberg AS, White RH, Keegan T, Wun T. Increased incidence of VTE in sickle cell disease patients: risk factors, recurrence and impact on mortality. Br J Haematol 2017; 178: 319-326.

26. Josephson CD, Su LL, Hillyer KL, Hillyer CD. Transfusion in the patient with sickle cell disease: a critical review of the literature and transfusion guidelines. Transfus Med Rev 2007; 21: 118-133.
27. Wahl S, Quirolo KC. Current issues in blood transfusion for sickle cell disease. Curr Opin Pediatr 2009; 21: 15-21.

28. Alhashimi D, Fedorowicz Z, Alhashimi F, Dastgiri S. Blood transfusions for treating acute chest syndrome in people with sickle cell disease. Cochrane Database Syst Rev 2010; CD007843.

29. Rosentsveyg J, Simonson JL, Chung SY, Koenig SJ, Zaidi GZ. A retrospective study to identify early predictors of mortality in sickle cell disease patients admitted to the intensive care unit. Am J Respir Crit Care Med 2019; 199: A1675.

\section{References}

${ }^{*}$ References should be primary source and numbered in the order in which they appear in the text. At the end of the article the full list of references should follow the Vancouver style.

* Unpublished data and personal communications should be cited only in the text, not as a formal reference.

* The author is responsible for the accuracy and completeness of references and for their correct textual citation.

* When a citation is referred to in the text by name, the accompanying reference must be from the original source.

* Upon acceptance of a paper all authors must be able to provide the full paper for each reference cited upon request at any time up to publication.

* Only 1-2 up to date references should be used for each particular point in the text.

Sample references are available from:

http://www.nlm.nih.gov/bsd/uniform_requirements.html 